\title{
Basal ganglia damage and impaired visual function in the newborn infant
}

Eugenio Mercuri, Janette Atkinson, Oliver Braddick, Shirley Anker, Frances Cowan, Mary Rutherford, Jackie Pennock, Lilly Dubowitz
Visual Development Unit, University College London

E Mercuri

J Atkinson

O Braddick

S Anker

\section{Department of} Paediatrics and Neonatal Medicine

E Mercuri

F Cowan

M Rutherford

L Dubowitz

R Steiner MRI Unit, Royal Postgraduate Medical School, Hammersmith Hospital, London M Rutherford

J Pennock

Correspondence to: Dr Eugenio Mercuri, Department of Paediatrics, Hammersmith Hospital, Du Cane Road,

London W12 OHN.

Accepted 10 March 1997

\begin{abstract}
Aim-To examine the effects of early lesions in the visual pathway on visual function; and to identify early prognostic indicators of visual abnormalities.

Methods-The visual function of 37 infants with perinatal brain lesions on magnetic resonance imaging was assessed using behavioural and electrophysiological variables.

Results-Normal visual behaviour was observed in most infants with large bilateral occipital lesions, but all the infants with associated basal ganglia involvement had abnormal visual function. Visual abnormalities were also present in six infants with isolated basal ganglia lesions. Conclusions-These observations suggest that basal ganglia may have an integral role in human visual development and that their presence on neonatal MRI could be an early marker of abnormal visual function.
\end{abstract}

(Arch Dis Child 1997;77:F111-F114)

Keywords: vision; MRI; visual evoked potentials; basal ganglia

Behavioural and electrophysiological methods of assessment that are suitable for infants have permitted new interpretations of human visual development in the first year of life. It is now generally accepted that the subcortical visual pathways have a major role in neonatal vision and that various aspects of visual function which require cortical visual modules progressively emerge in the first months of postnatal life. ${ }^{12}$ In neonates a lesion involving cortical structures has little or no effect on the mainly subcortical visual function, ${ }^{3}$ but it has been assumed that a lesion involving the visual cortex would cause abnormalities of those aspects of visual function which mature later in infancy. In infants and children with brain lesions of perinatal origins neither the pattern nor the severity of visual function can be readily predicted from the type or extent of the involvement of the cortical structures as seen on magnetic resonance imaging (MRI). ${ }^{4-6}$

This study has exploited new techniques to give a more detailed assessment of visual function and its correlation with both cortical and subcortical structures. The aim was to examine the functional effects of early lesions in the visual pathway and to identify early prognostic indicators of visual abnormalities.

\section{Methods}

The children recruited into this study were born in, or referred soon after birth, to the Hammersmith Hospital, London. As part of an ongoing study aimed at documenting the evolution of perinatal brain lesions, all those with hypoxic ischaemic encephalopathy (HIE) or abnormal neurological signs undergo MRI in the neonatal period and are referred for assessment of visual function.

MRI was performed using a Picker $1.0 \mathrm{~T}$ HPQ system using $\mathrm{T} 1$ and T2 weighted spin-echo (SE) and age related inversion recovery (IR) sequences in the transverse plane. Lesions were recorded by the consensus of two observers looking for the location and the extent of the lesions, paying particular attention to the involvement of the occipital cortex, optic radiation, midbrain and basal ganglia.

Vision was evaluated by using the Atkinson Battery of Child Development for Examining Functional Vision (ABCDEFV). ${ }^{7}$ This includes assessment of ocular movements, pupil response, refractive errors, and the following tests of more complex visual functions:

Acuity was tested by using automated forced choice preferential looking. Stimuli comprised black and white stripes of varying spatial frequencies paired with a uniform grey background displayed at the infant's eye level. Acuity was measured as the finest grating for which the infant shows a consistent preference.

Binocular optokinetic nystagmus (OKN) was elicited using a large monitor displaying a pattern of random dots which could be moved laterally in either direction in front of the infant's eyes. The presence and the symmetry of the response in each direction were recorded.

Visual fields were measured by gradually moving a small white ball (40 $\mathrm{mm}$ diameter) from 90 degrees laterally inwards towards the midline. Eye and head movements were observed to estimate the border of the visual fields and their symmetry.

Attention over distance was tested evaluating the distance at which the infant is able to maintain attention on a coloured toy presented on the midline in front of the eyes and gradually moved further away. The distance at which fixation is lost is taken as the measure of the attention over distance.

Fixation shift was tested evaluating the direction and latency of saccadic eye movements in response to the onset of a peripheral visual stimulus (black and white stripes) in the lateral field. A central target consisting of a high con- 


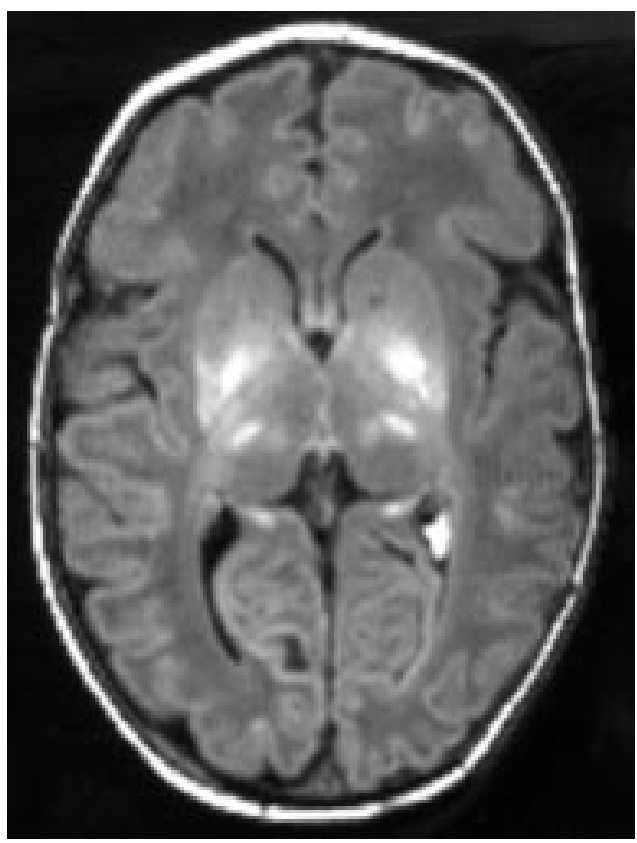

Figure 1 Boy aged 2 weeks. T1 weighted spin-echo sequence [TE 860/20] showing, bilateral abnormal signal intensity in the posterior aspects of the putamen and thalamus. This child had multiple abnormalities on both the visual assessments performed at 3 and 6 months.

trast schematic face was used as a fixation stimulus before the introduction of the peripheral target, and as a competition stimulus in addition to it. In some trials the central target disappeared simultaneously with the appearance of the peripheral target (non-competition) while in others the face target remained visible when the peripheral target appeared on the monitor (competition). Longitudinal studies in normal babies have shown that during "noncompetition" normal refixations can be observed from the first week of life, but disengagement from the central target, when "competition" is a more cortically mediated function, is absent or slower up to 3 to 4 months of age. ${ }^{9}$

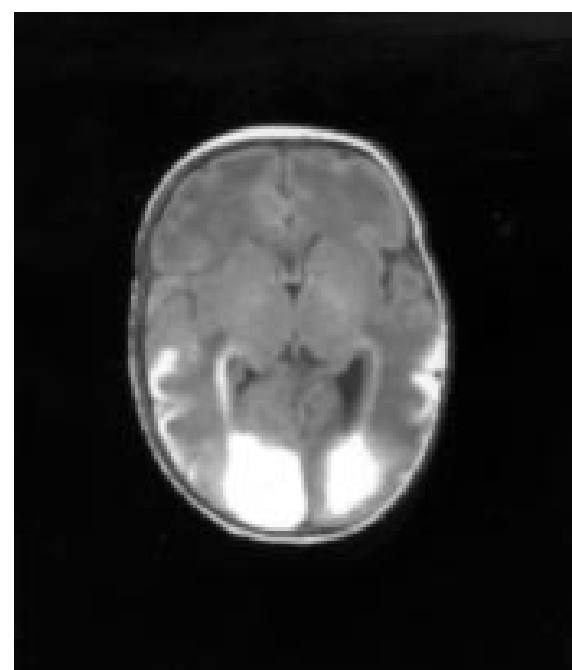

Figure 2 Correlation between MRI and visual findings: * generalised cortical lesions involving occipital cortex; ocul mov ocular movement; OKN optokinetic nystagmus; fix'n shift fixation shift; att dist attention at distance.
Orientation reversal visual evoked potentials The recording electrode was placed in $\mathrm{Oz}$, the reference at $\mathrm{Fz}$, and the earth on the vertex. Stimuli consisted of black and white stripes at a spatial frequency of 0.52 cycle/degree. Ninety degree changes between opposite oblique orientations were embedded in a sequence of random phase shifts at a temporal frequency of 8 reversals /second. The signal was averaged from at least 250 sweeps. The results were analysed using a circular variance test of the consistency of signal phase. ${ }^{10}$ Our previous longitudinal studies in normal babies have shown that these signals are absent at birth and that they progressively develop in the first four months of life. The absence of a significant response from 15 weeks has to be considered abnormal. ${ }^{11}$

As all these responses are normally present by 5 months of age, we report only the results of visual assessment performed after 6 months of age.

\section{Results}

Thirty seven infants were included in the study. Their ages ranged from 6 to 31 months (mean age 10.8 months).

Twenty nine infants showed changes consistent with a diagnosis of HIE and eight showed multifocal lesions of various aetiologies. The cohort was divided according to the involvement of visual cortex, optic radiation, and basal ganglia on MRI. Fifteen of the 31 infants studied only showed generalised oedema on the initial MRI or minor ventricular dilatation, but subsequently showed a normal scan after the first weeks of life. Nine infants showed generalised lesions with bilateral involvement of the occipital cortex and optic radiation but intact basal ganglia. Six infants showed isolated basal

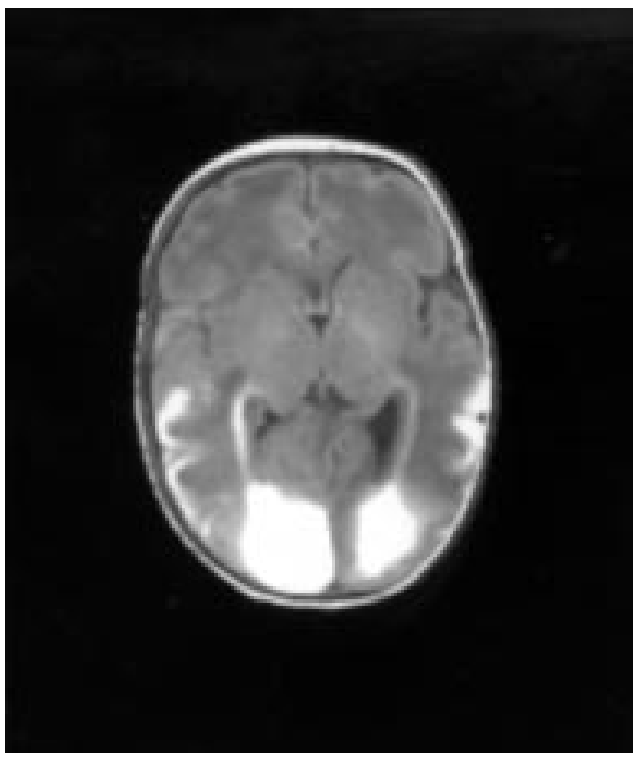

Figure 3 Boy aged 2 weeks. T1 weighted spin-echo sequence [TE 860/20], showing bilateral haemorrhagic lesions involving the occipital pole and additional haemorrhagic involvement of both temporal lobes. There are no abnormal signal intensities in the basal ganglia and talami. This child tested normal on all the visual tests used. 


\begin{tabular}{|c|c|c|c|c|c|c|c|c|c|c|c|}
\hline \multirow[b]{2}{*}{ No } & \multirow[b]{2}{*}{ Diagnosis } & \multirow{2}{*}{$\begin{array}{l}\text { Age test } \\
\text { (months) }\end{array}$} & \multicolumn{3}{|c|}{ Ocular movements } & \multirow[b]{2}{*}{$O K N$} & \multirow[b]{2}{*}{ Acuity } & \multirow[b]{2}{*}{ Visual fields } & \multirow{2}{*}{$\begin{array}{l}\text { Attention } \\
\text { distance }\end{array}$} & \multirow[b]{2}{*}{ Fixation shift } & \multirow[b]{2}{*}{$V E P$} \\
\hline & & & Tracking & Strabismus & Nystagmus & & & & & & \\
\hline 1 & HIE & 6 & $\mathrm{~N}$ & & & $\mathrm{~N}$ & $\mathrm{~N}$ & $\mathrm{~N}$ & $\mathrm{~N}$ & $\mathrm{~N}$ & $\mathrm{~N}$ \\
\hline 2 & HIE & 6 & $\mathrm{~N}$ & & & $\mathrm{~N}$ & $\mathrm{~N}$ & $\mathrm{~N}$ & $\mathrm{~N}$ & $\mathrm{~N}$ & $\mathrm{~N}$ \\
\hline 3 & HIE & 6 & $\mathrm{~N}$ & & & $\mathrm{~N}$ & $\mathrm{~N}$ & $\mathrm{~N}$ & $\mathrm{~N}$ & $\mathrm{~N}$ & $\mathrm{~N}$ \\
\hline 4 & HIE & 5 & $\mathrm{~N}$ & & & $\mathrm{~N}$ & $\mathrm{~N}$ & $\mathrm{~N}$ & $\mathrm{~N}$ & $\mathrm{~N}$ & $\mathrm{~N}$ \\
\hline 5 & HIE & 15 & $\mathrm{~N}$ & & & $\mathrm{~N}$ & $\mathrm{~N}$ & $\mathrm{~N}$ & $\mathrm{~N}$ & $\mathrm{~N}$ & N/A \\
\hline 6 & HIE & 5 & $\mathrm{~N}$ & & & $\mathrm{~N}$ & $\mathrm{~N}$ & $\mathrm{~N}$ & $\mathrm{~N}$ & $\mathrm{~N}$ & $\mathrm{~N}$ \\
\hline 7 & HIE & 5 & $\mathrm{~N}$ & & & $\mathrm{~N}$ & $\mathrm{~N}$ & $\mathrm{~N}$ & $\mathrm{~N}$ & bil abn & $\mathrm{N}$ \\
\hline 8 & HIE & 10 & $\mathrm{~N}$ & & & $\mathrm{~N}$ & $\mathrm{~N}$ & $\mathrm{~N}$ & $\mathrm{~N}$ & $\mathrm{~N}$ & $\mathrm{~N}$ \\
\hline 9 & HIE & 6 & $\mathrm{~N}$ & & & $\mathrm{~N}$ & $\mathrm{~N}$ & $\mathrm{~N}$ & $\mathrm{~N}$ & $\mathrm{~N}$ & $\mathrm{~N}$ \\
\hline 10 & HIE & 6 & $\mathrm{~N}$ & & & $\mathrm{~N}$ & $\mathrm{~N}$ & $\mathrm{~N}$ & $\mathrm{~N}$ & $\mathrm{~N}$ & $\mathrm{~N}$ \\
\hline 11 & HIE & 5 & $\mathrm{~N}$ & & & $\mathrm{~N}$ & $\mathrm{~N}$ & $\mathrm{~N}$ & $\mathrm{~N}$ & $\mathrm{~N}$ & $\mathrm{~N}$ \\
\hline 12 & HIE & 5 & $\mathrm{~N}$ & & & $\mathrm{~N}$ & $\mathrm{~N}$ & $\mathrm{~N}$ & $\mathrm{~N}$ & $\mathrm{~N}$ & $\mathrm{~N}$ \\
\hline 13 & HIE & 22 & $\mathrm{~N}$ & & & $\mathrm{~N}$ & $\mathrm{~N}$ & $\mathrm{~N}$ & $\mathrm{~N}$ & $\mathrm{~N}$ & $\mathrm{~N}$ \\
\hline 14 & HIE & 13 & $\mathrm{~N}$ & & & $\mathrm{~N}$ & $\mathrm{~N}$ & $\mathrm{~N}$ & $\mathrm{~N}$ & $\mathrm{~N}$ & $\mathrm{~N}$ \\
\hline 14 & HIE & 13 & $\mathrm{~N}$ & & & $\mathrm{~N}$ & $\mathrm{~N}$ & $\mathrm{~N}$ & $\mathrm{~N}$ & $\mathrm{~N}$ & $\mathrm{~N}$ \\
\hline 15 & HIE & 10 & $\mathrm{~N}$ & & & $\mathrm{~N}$ & $\mathrm{~N}$ & $\mathrm{~N}$ & $\mathrm{~N}$ & $\mathrm{~N}$ & $\mathrm{~N}$ \\
\hline 16 & HIE & 11 & Poor & RCS & & $\mathrm{N}$ & $\mathrm{N}$ & $\mathrm{R}$ loss & $\mathrm{N}$ & $\mathrm{R}$ abn $\mathrm{C}$ & 8 or NS \\
\hline 17 & HIE & 17 & $\mathrm{~N}$ & RDS & & asym & $\mathrm{N}$ & $\mathrm{N}$ & $\mathrm{N}$ & bil abn C & N/A \\
\hline 18 & HIE & 6 & Poor & ACS & & $\mathrm{N}$ & Reduced & Not testable & Reduced & bil abn $\mathrm{C}$ & 8 or NS \\
\hline 19 & HIE & 6 & $\mathrm{~N}$ & & & $\mathrm{~N}$ & $\mathrm{~N}$ & $\mathrm{~N}$ & $\mathrm{~N}$ & $\mathrm{~N}$ & 8 or NS \\
\hline 20 & multifoc & 6 & $\mathrm{~N}$ & & & $\mathrm{~N}$ & $\mathrm{~N}$ & $\mathrm{~N}$ & $\mathrm{~N}$ & $\mathrm{~N}$ & $\mathrm{~N}$ \\
\hline 21 & multifoc & 6 & $\mathrm{~N}$ & & & $\mathrm{~N}$ & $\mathrm{~N}$ & $\mathrm{~N}$ & $\mathrm{~N}$ & $\mathrm{~N}$ & $\mathrm{~N}$ \\
\hline 22 & multifoc & 6 & $\mathrm{~N}$ & & & $\mathrm{~N}$ & $\mathrm{~N}$ & L loss & $\mathrm{N}$ & $\mathrm{N}$ & $\mathrm{N}$ \\
\hline 23 & multifoc & 7 & $\mathrm{~N}$ & & & $\mathrm{~N}$ & $\mathrm{~N}$ & bil narrow & $\mathrm{N}$ & bil abn $\mathrm{C}$ & $\mathrm{N}$ \\
\hline 24 & multifoc & 7 & $\mathrm{~N}$ & & & $\mathrm{~N}$ & $\mathrm{~N}$ & $\mathrm{~N}$ & $\mathrm{~N}$ & $\mathrm{~N}$ & $\mathrm{~N}$ \\
\hline 25 & HIE & 14 & $\mathrm{~N}$ & & & $\mathrm{~N}$ & $\mathrm{~N}$ & $\mathrm{~N}$ & Reduced & bil abn Nc/C & N/A \\
\hline 26 & HIE & 23 & Poor R & & + & $\mathrm{N}$ & Reduced & L loss & Reduced & bil abn $\mathrm{C}$ & 8 or NS \\
\hline 27 & HIE & 5 & $\mathrm{~N}$ & & & $\mathrm{~N}$ & $\mathrm{~N}$ & $\mathrm{R}$ loss & Reduced & $\mathrm{R}$ abn $\mathrm{C}$ & 8 or NS \\
\hline 28 & HIE & 7 & Poor & ADS & & asym & Not testable & Not testable & Reduced & bil abn $\mathrm{Nc} / \mathrm{C}$ & 8 or NS \\
\hline 29 & HIE & 7 & Poor & & & $\mathrm{N}$ & Not testable & Not testable & Reduced & bil abn Nc/C & $8 \mathrm{Ph} /$ or NS \\
\hline 30 & HIE & 17 & $\mathrm{~N}$ & & & asym & Reduced & L loss & Reduced & bil abn $\mathrm{Nc} / \mathrm{C}$ & N/A \\
\hline 31 & HIE & 12 & $\mathrm{~N}$ & ACS & + & asym & Reduced & Not testable & Reduced & bil abn $\mathrm{Nc} / \mathrm{C}$ & 8 or NS \\
\hline 32 & HIE & 6 & Poor & LCS & & asym & Reduced & bil narrow & Reduced & bil abn $\mathrm{C}$ & $8 \mathrm{Ph} /$ or NS \\
\hline 33 & HIE & 31 & Poor R & LDS & & asym & Reduced & $\mathrm{R}$ loss & Reduced & bil abn $\mathrm{Nc} / \mathrm{C}$ & 8 or NS \\
\hline 34 & HIE & 5 & Poor & & & asym & Reduced & Not testable & Reduced & bil abn Nc/C & $4 / 8$ or NS \\
\hline 35 & multifoc & 17 & Poor & ACS & & asym & Reduced & bil narrow & Reduced & bil abn $\mathrm{Nc} / \mathrm{C}$ & N/A \\
\hline 36 & multifoc & 5 & Poor & ADS & & asym & Reduced & Not testable & Reduced & bil abn $\mathrm{Nc} / \mathrm{C}$ & $4 / 8$ or NS \\
\hline 37 & multifoc & 6 & Poor & ACS & & asym & Reduced & L loss & Reduced & bil abn Nc/C & $4 / 8$ or NS \\
\hline
\end{tabular}

$\mathrm{HIE}=$ hypoxic ischaemic encephalopathy multifoc $=$ multifocal $; \mathrm{m}=$ months $\mathrm{N}=$ normal; $\mathrm{R}=$ right $; \mathrm{L}=$ left RCS = right convergent strabismus; RDS = right divergent strabismus; $\mathrm{ADS}=$ alternating divergent strabismus; $\mathrm{ACS}=$ alternating convergent strabismus; LCS = left convergent strabismus; $\mathrm{LDS}=$ left divergent
strabismus; asym = asymmetrical, bil = bilateral; $\mathrm{abn}=$ abnormal; $\mathrm{Nc}=$ non-competition; $\mathrm{C}=$ competition; $\mathrm{N} / \mathrm{A}=\mathrm{not}$ available; or = orientation-reversal; Ph = strabismus; asym $=$ asymmetrical, bil $=$ bilateral; abn $=$ abnormal;
phase-reversal; $8=8 \mathrm{rev} / \mathrm{sec} ; 4=4 \mathrm{rev} / \mathrm{sec} ; \mathrm{NS}=$ not significant.

ganglia lesions (all bilateral) (fig 1) and seven generalised lesions including involvement of occipital cortex, optic radiation, and basal ganglia.

Details of the results on tests assessing visual function are shown in table 1 .

Figure 2 shows the details of the correlation between MRI and the various aspects of visual function assessed. All 15 infants with a normal MRI after the end of the first week also showed normal visual function on all the tests. Four of the nine infants with diffuse cortical involvement but intact basal ganglia had normal visual function (fig 3). Three showed multiple visual abnormalities and two abnormal fields only. None of the six infants with isolated basal ganglia lesions showed completely normal visual function. All showed abnormal fixation shift and visual evoked potentials, with a variety of abnormalities on the other tests. All seven infants with diffuse involvement of both occipital cortex and basal ganglia showed severe abnormalities on all the aspects of visual function assessed.

\section{Discussion}

Our observations suggest that in infants lesions involving the basal ganglia are more likely to be associated with impaired visual function than lesions of the occipital cortex. More specifically, it was the involvement of the posterior aspects of the putamen that were always

\section{Key messages}

- In agreement with previous animal studies, our study has suggested that basal ganglia may play an important role in infant's vision.

- The involvement of basal ganglia on neonatal MRI, seems to be more often associated with impaired visual function than lesions involving the visual occipital cortex.

- A wide battery of tests is necessary to evaluate various aspects of visual function.

associated with abnormal visual function. The involvement of occipital cortex and optic radiation, but preserved putamen, tended to be associated with only minor visual abnormalities or none at all, the concomitant bilateral involvement of the putamen was always associated with severe abnormalities of all aspects of visual function evaluated. This difference could not be explained by a difference in the extent of the hemispheric involvement, which was similar in the two groups. The effect of damage in the putamen was also demonstrated by the high prevalence of visual abnormalities in infants who showed bilateral abnormalities of the putamen but normal visual cortex and optic radiation. Lesions of the caudate nucleus, globus pallidus, and thalamus were observed only in a few infants and always in association with lesions in the putamen. Their presence 
was not associated with an increased severity of visual impairment.

As far as we are aware, this is the first description of the role of basal ganglia in visual function in human infants. Previous studies which have investigated the correlation between visual function and structure on MRI have only correlated visual function with the possible involvement of occipital cortex or optic radiation and have not reported the status of the basal ganglia. ${ }^{4512}$ Only one study using cranial ultrasound in preterm infants suggested a possible role for the basal ganglia in infants' visual behaviour, ${ }^{3}$ but this study only evaluated visual function in the neonatal period and no details of the involvement of the basal ganglia were possible on cranial ultrasonography. However, neuroanatomical studies of animals have shown extensive reciprocal connections in both directions between visual cortical areas and the striatum (putamen and caudate). ${ }^{13-17}$ Studies both in animals with experimental lesions and in patients have emphasised the role of the basal ganglia in modulating saccadic eye movements and in controlling spatial attention. ${ }^{17-21}$ This role is consistent with the deficits shown in the visual fields of the babies studied, and fixation shift and might be also expected to affect the preferential looking method used to assess acuity. It is striking that basal ganglia damage is also strongly associated with abnormal VEP responses, usually thought to be based entirely on cortical function. These results suggest that the normal development of cortical areas themselves may depend on the integrity of connections with the basal ganglia. In contrast, however, the involvement of basal ganglia seemed to produce little effect on simple ability to elicit a full range of ocular movements, including $\mathrm{OKN}$, which are presumably largely served by the midbrain. The absence of abnormal ocular movements in the children with isolated basal ganglia lesions argues against the possibility that minor lesions of the midbrain not detectable by MRI might occur in association with basal ganglia lesions and be partly responsible for visual impairment. In contrast, we cannot exclude that basal ganglia lesions might be accompanied by other minor lesions involving other structures of the visual pathway, which are undetectable on MRI. Nevertheless, our results clearly indicate that lesions in the putamen on neonatal MRI are a more sensitive marker of abnormal visual behaviour than the involvement of the occipital cortex. At present, this statement can only be made about the period up to 6 months of age, when the assessments took place. Further longitudinal studies are needed to evaluate not only whether the infants with basal ganglia lesions will show permanent visual difficulties but also whether, in the infants with occipital lesions who show normal visual function at 6 months, impairments become apparent as visual function matures.

1 Bronson GW. The postnatal growth of visual capacity. Child Dev 1974;45:873-90.

2 Atkinson J. Human visual development over the first 6 months of life. A review and a hypothesis. Hum Neurobiol months of life.

3 Dubowitz LMS, de Vries L, Mushin J, Arden GB. Visual function in the newborn infant: it is cortically mediated? Lancet 1986;i:1139-41.

4 Pike MG, Holstrom G, de Vries LS, Pennock JM, Drew KJ, Sonksen PM, et al. Patterns of visual impairment associated with lesions of the preterm infants. Dev Med Child Neurol 1994;36:849-62

5 Cioni G., Fazzi B, Ipata A, Canapicchi R, Van Hof-van duin $\mathrm{J}$. Correlation between cerebral visual impairment and MR imaging in children with neonatal encephalopathy. Dev Med Child Neurol 1996;38:120-32

6 Mercuri E, Atkinson J, Braddick O, Anker S, Nokes L, Cowan F, et al. Visual function in infants with cerebral infCowan F, et al. Visual function in infants with
arction. Arch Dis Child 1996;75:F73-F82.

7 Atkinson J. The Cambridge assessment and screening of vision in high risk infants and young children. In: NJ Anastiow and S Harel, eds. At risk infants: interventions, families and research. Baltimore: Brookes Publish Co Inc: 1993:33-45.

8 Atkinson J, Van Hof van Duin J. Assessment of normal and abnormal vision during the first year of life. In Fielder A, Bax B, eds. Management of visual handicap in childhood. Ambridge: Mac Keith Press, 1993:9-29.

9 Hood B, Atkinson J. Disengaging visual attention in the infant and adult. Infant Behav Dev 1993;16:405-22.

10 Wattam-Bell J. Analysis of infant visual evoked potentials (VEPs) by a phase sensitive statistic. Perception (VEPs) by

11 Braddick O. Orientation and motion-selctive mechanisms in infants. In Simons K, ed. Infant vision: basic and clinical research. Oxford: Oxford University Press, 1993:163-77.

12 Eken P, de Vries LS, van der Graaf Y, Meiners LC, van Nieuwenhuisen O. Haemorrhagic ischaemic lesions of the neonatal brain: correlation between cerebral visual impairment, neurodevelopmental outcome and MRI in infancy. Dev Med Child Neurol 1995;37:41-55.

13 Ungerleider LG, Desimone R, Galwin TW, Mishkin M. Subcortical proiections of area MT in the macaque. $f$ Comp Neurol 1984;223:368-86.

14 Takada $M$. The lateroposterior thalamic nucleus and substantia nigra pars lateralis: origin of dual innervation substantia nigra pars lateralis: origin of dual innervation 1992;139:153-6.

15 Updyke BV. Organisation of visual corticostriatal projections in the cat, with observations on visual projections to claustrum and amygdala $\mathcal{f}$ Comp Neurol 1993;327:159-93.

16 Serizawa M, Mc Haffie JG, Hoshino K, Norita M. Corticostriatal and corticotectal projections from visual cortical areas 17,18 and 18a in the pigmented rat. Arch Histol Cytol 1994;57:493-507.

17 Kennard C, Lueck CJ. Oculomotor abnormalities in disease of the basal ganglia. Rev Neurol (Paris) 1989;145:587-95.

18 Kato M, Miyashita N, Hikosaka O, Matsamura M, Usui S, Kori A. Eye movements in monkeys with local dopamine Kori A. Eye movements in monkeys with local dopamine
depletion in the caudate nucleus. I: deficits in the spontaneous saccades. F Neurosci 1995;15:912-27.

19 Wurtz RH, Hikosaka O. Role of the basal ganglia in the initiation of saccadic eye movements. Progr Brain Res tiation of sacca

20 Kermadi I, Boussaoud D. Role of the primate sriatum in attention and sensorimotor processes: comparison with premotor cortex. Neuroreport 1995;6:1177-81.

21 Miyashita N, Hikosaka O, Kato M. Visual hemineglect induced by unilateral striatal dopamine deficiency in monkeys. Neuroreport 1995;6:1257-60. 